\title{
PERCEPTION OF ENVIRONMENTAL EDUCATION PROCESS AND PRODUCTION OF SOLID WASTE FOR ELEMENTARY SCHOOL STUDENTS
}

\author{
COSTA, Camila de Carvalho; ROCHA, José Roberto Caetano da* \\ Universidade Estadual do Paraná (UNESPAR) - Campus Paranaguá, Colegiado de Ciências Biológicas, Rua \\ Comendador Correa Junior, 117, CEP 83.203-560, Paranaguá - PR, Brasil \\ (fone: +55 413423 3644; fax: +55 413423 1611) \\ ${ }^{*}$ Autor correspondente \\ e-mail: jose.rocha@unespar.edu.br
}

January 2017; received in revised form 02 March 2017; accepted 10 March 2017

\section{RESUMO}

Nesse estudo avaliou-se o conhecimento que estudantes do ensino fundamental têm sobre o meio ambiente e sobre o processo de separação dos resíduos sólidos produzidos diariamente em suas residências. Esta pesquisa foi realizada com alunos dos $7^{\circ}, 8^{\circ}$ e $9^{\circ}$ anos de uma escola estadual localizada no município de Paranaguá, PR. Nele ponderou-se sobre algumas medidas preventivas que possam amenizar o problema ocasionado pelo descarte inadequado desses materiais e se eles conseguem observar algum valor econômico nos resíduos sólidos produzidos. Assim no mesmo se teve como principais objetivos o questionamento sobre a quantidade de resíduos sólidos produzidos em seus lares. Avaliar se as pessoas realizam a separação seletiva dos mesmos. Além de quantificar e conhecer a destinação final dos resíduos sólidos produzidos diariamente por eles. Através da metodologia utilizada se percebeu que mesmo o questionário sendo aplicado em séries diferentes do ensino fundamental as respostas apresentadas demonstraram pouca variação de uma turma para outra. Portanto mesmo em séries subsequentes se percebe que ocorreu pouca interiorização dos conteúdos ambientais apresentados. Esse fato demonstra ainda que o processo cultural suplanta o processo ensinoaprendizagem, visto que as atitudes dos alunos contradizem o discurso que eles adquiriram em sala de aula.

Palavras-chave: Meio ambiente; processo ensino-aprendizado; contextualização; resíduos sólidos.

\section{ABSTRACT}

In this study evaluated the knowledge that elementary school students have about the environment and about the process of separating the solid waste produced daily in their homes. This research was carried out with students of the 7th, 8th and 9th years of a state school located in the city of Paranaguá, PR. In it we considered some preventive measures that could alleviate the problem caused by the inadequate disposal of these materials and if they can observe some economic value in the solid waste produced. Thus, the main objectives were the questioning about the amount of solid waste produced in their homes. Evaluate if people perform the selective separation of the same. In addition to quantify and know the final destination of solid waste produced daily by them. Through the methodology used it was noticed that even the questionnaire being applied in different series of elementary school the answers presented showed little variation from one class to another. Therefore even in subsequent series it is noticed that there was little internalization of the presented environmental contents. This fact also demonstrates that the cultural process supplants the teaching-learning process, since the students' attitudes contradict the discourse they have acquired in the classroom.

Keywords: Environment; teaching-learning process; contextualization; solid waste. 


\section{INTRODUÇÃO}

O homem necessita de recursos naturais para produzir bens e serviços que Ihe são úteis, sendo que os rejeitos de materiais e energia que não são utilizados no processo de extração retornam ao meio ambiente sem qualquer tratamento ou preocupação dos problemas ambientais ocasionados. Este fato acontecia de forma sistemática e contundente em todos os processos extrativistas, porém, ao longo da história, pesquisadores perceberam os graves problemas ambientais ocasionados por essa prática. E para reverter esses problemas refletiram criticamente sobre a relação entre ciência, tecnologia e sociedade e assim resgatou-se o papel da Educação Ambiental (SANTOS, 2007).

No Brasil, sobre o tema "Educação Ambiental" algumas leis foram promulgadas ao longo de sua história republicana. Porém a necessidade efetiva de legislação específica sobre Educação Ambiental surgiu com a Constituição Federal de 1988. Nela existem nove artigos (5, 20, 23, 24, 129, 170, 174, 216 e 225) que apresentam dispositivos referentes ao meio ambiente. Sendo que nos mesmos se discute as competências e as responsabilidades da União, dos Estados, dos Municípios e do Distrito Federal no tocante a preservação da natureza (BRASIL, 2012a).

A Lei de Diretrizes e Bases da Educação Brasileira, 9.394 de 1996, que deveria ter instrumentos relacionados a essa forma de ensino, não cita nenhum item específico sobre o tema de Educação Ambiental. Esse tema é tratado de forma menos contundente, porém bastante eficaz, quando considera a compreensão do ambiente natural na formação básica do cidadão naquele período escolar denominado de Ensino Fundamental no Brasil (MORADILLO e OKI, 2004).

A partir desse enfoque, outro fato importante que aconteceu foi a inclusão do Meio Ambiente como argumento contextualizador e motivador no processo ensino-aprendizagem. Esses conceitos são discutidos de forma incisiva nos Parâmetros Curriculares Nacionais do Ensino Fundamental de 1997. Nele a questão ambiental é considerada como um fato cada vez mais urgente e importante para a sociedade, pois o futuro da humanidade depende da relação estabelecida entre a natureza e o uso pelo homem dos recursos naturais disponíveis. Por estas razões, verificou-se a importância e a necessidade de se incluir a temática do Meio Ambiente como tema dos currículos escolares, permeando toda prática educacional e não somente uma disciplina ou um núcleo comum (BRASIL, 1997).

Posteriormente, com a promulgação da lei 9.795 de abril de 1999 instituiu-se a Política Nacional de Educação Ambiental no Brasil. Assim o primeiro artigo dessa lei direcionou-se para os possíveis fatores positivos que a mesma produziria, ou seja, acreditava-se que com a implantação da mesma haveria a construção de valores sociais, conhecimentos, habilidades, atitudes e competências voltadas para a conservação do meio ambiente, assim esse bem que é considerado de uso comum do povo, e essencial à sadia qualidade de vida e de sua sustentabilidade.

Já no segundo artigo da mesma lei definiu-se o escopo e a abrangência que essa lei atingirá, ou seja, a

"educação ambiental será um componente essencial e permanente da educação nacional, devendo estar presente, de forma articulada, em todos os níveis e modalidades do processo educativo brasileiro, em caráter formal e não formal" (BRASIL, 1999).

Para fechar esse ciclo inicial o Plano Nacional de Educação - PNE (2001-2010) aprovado pelo Congresso Nacional (Lei 10.172/2001), além de cumprir uma determinação da LDBEN em seu art.87, fixou diretrizes, objetivos e metas para o período de 10 anos, garantindo assim a coerência nas prioridades educacionais para este período. Nos objetivos e metas para o ensino fundamental e ensino médio, o PNE definiu-se que:

"A Educação Ambiental, será tratada como tema transversal, e a mesma será desenvolvida como uma prática educativa integrada, contínua e permanente em conformidade com a Lei n. 9 9795/99" (BRASIL, 2001).

Este plano discutido com todos os setores da sociedade envolvidos na educação representou um avanço da questão ambiental no 
universo da educação.

Para evitar o equívoco inicial na LDB 9394 em 2012 o Art. 29 da Lei $N^{0} 12.608$ estabelece que as diretrizes e bases da educação nacional, passa a vigorar acrescido do seguinte $\S 7^{\circ}$ "Os currículos do ensino fundamental e médio devem incluir os princípios da proteção e defesa civil e a educação ambiental de forma integrada aos conteúdos obrigatórios." (BRASIL, 2012b)

Para tanto, o processo de Educação Ambiental hoje deve ter conteúdo e aprendizado, motivo e motivação, parâmetro e norma. Esse processo necessita ir além dos conteúdos pedagógicos, deve interagir com o ser humano de forma que a troca seja uma retroalimentação positiva para ambos. Portanto os educadores ambientais devem ser pessoas apaixonadas pelo que fazem. E, para que o respeito seja o primeiro sentimento motivador das ações, se torna necessário que a escola mude suas regras para se fazer educação ambiental de uma forma mais humana (CARVALHO, 2006).

Alguns pesquisadores entendem que a escola é um espaço privilegiado para estabelecer conexões e obter informações. Neste espaço pode-se criar condições e alternativas que estimulem os alunos a terem concepções e posturas de diferentes vertentes filosóficas. E com elas torná-los cientes de suas responsabilidades e, principalmente, se perceberem como integrantes do meio ambiente. Não esquecendo do fato, de que a educação formal continua um importante espaço para o desenvolvimento de valores e atitudes comprometidas com a sustentabilidade ambiental e social (CUBA, 2010).

Dias (2004) é mais enfático quando indica que a Educação Ambiental na escola não deve ser apenas conservacionista. Não deve ser aquela educação cujos ensinamentos conduzem somente ao uso racional dos recursos naturais e à manutenção de um nível ótimo de produtividade dos ecossistemas naturais ou gerenciados pelo homem. Mas deve ser aquela educação voltada para o meio ambiente que implica em uma profunda mudança de valores, e em uma nova visão de mundo, o que ultrapassa bastante 0 estado conservacionista. Não somente conservar, mas antes prever e rever a necessidade e uso dos recursos naturais (BOMFIM, 2013).

Percebe-se ainda que a quantidade e o destino dos resíduos produzidos nas casas dos estudantes, na maioria das vezes, não entram na pauta das discussões, seja no âmbito familiar, escolar e comunitário. As pessoas querem se ver livres do resíduo produzido e acumulado, porém as mesmas não têm e não querem ter a mínima ideia de onde e de que forma esses resíduos sólidos são descartados e/ou depositados. Muito menos conseguem diferenciar entre o que é um aterro sanitário e um lixão, bem como o tipo de destino físico existente em sua cidade.

Nesse sentido se torna importante que após o longo período de sua promulgação até os dias atuais se avalie o nível de abrangência que realmente foi atingido com a documentação relativa à Educação Ambiental (BRASIL 2010). Se os cidadãos que estão sendo formados no Ensino Básico realmente estão construindo valores sociais e socioambientais que garantam a qualidade de vida das gerações futuras. Inclusive verificar se os mesmos adquiriram habilidades, atitudes e competências voltadas para a conservação do ambiente onde vivem como preconizados nos documentos legislativos produzidos.

\section{METODOLOGIA:}

Esta pesquisa foi realizada com noventa alunos das três últimas séries do ciclo II do ensino fundamental localizada no município de Paranaguá, PR. Os alunos têm entre onze e quinze anos de idade, portanto já se percebe que alguns ultrapassaram a idade cronológica desejável para essa fase escolar. Para tanto, aplicou-se um questionário de múltipla escolha, visando observar o conhecimento dos alunos em relação aos aspectos socioambientais da cidade de Paranaguá em relação a produção e destinação dos resíduos sólidos. Durante a discussão sempre relacionou-se esses resíduos ao lixo sólido produzido. As questões versavam principalmente em relação a quantidade de resíduo sólido produzido por habitante e a destinação do mesmo. Bem como a avaliação das pessoas responsáveis por cada uma dessas etapas. Eram avaliadas ainda a questão do processo de reciclagem e de reuso desses materiais.

Na Tabela 1, apresentada nos anexo, é possível observar o teor das questões que foram dirigidas a esses alunos, visando principalmente identificar a quantidade de pessoas avaliadas, 
bem como determinar a quantidade aproximada de resíduo sólido produzido por esse grupo de pessoas. Outro fator importante avaliado foi verificar se essas pessoas optam principalmente por diminuir a quantidade de resíduos produzidos ou se optam por reciclar o mesmo.

Nesse questionário prezou-se para que os alunos pesquisados ficassem anônimos e assim eles respondessem de forma mais livre e sincera cada uma das questões.

Ao final do processo, abriu-se para discussão para que fosse melhor detalhado cada uma das respostas. E assim se percebeu algumas incoerências que será relatada a seguir.

\section{RESULTADOS E DISCUSSÃO:}

De acordo com a Tabela 2, apresentada em anexo, é possível comparar o número de respostas que os alunos indicaram para cada um dos questionamentos indicados no questionário que foi apresentado na Tabela 1.

Ao avaliar as respostas da primeira questão proposta, é possível perceber que a maioria dos alunos se diz preocupada com o meio ambiente. Principalmente os alunos do $9^{\circ}$ ano, no qual todos foram incisivos em responder que sim. Talvez devido a idade cronológica dos mesmos, ou ainda devido ao fato de que os conceitos ambientais permeiam os conteúdos programáticos nas diferentes disciplinas que os mesmos tiveram até aqui.

As respostas da pergunta sobre o destino final dos resíduos sólidos da cidade mostraram que esses alunos têm pouca ou quase nenhuma informação sobre o fato, visto que em torno de $50 \%$ deles responderam que não sabem sobre a destinação final dos resíduos. Avaliando especificamente as respostas dos alunos dos $7^{\circ}$ e $8^{\circ}$ anos se percebeu, durante as discussões, que parte dos $40 \%$ que responderam sim, apresentavam dúvidas sobre 0 destino final desses resíduos. Durante as discussões com os alunos do $9^{\circ}$ ano se observou que alguns conhecem plenamente que em Paranaguá, os resíduos sólidos são depositados em um lixão. Fato esse que é extremamente questionável devido a vários fatores entre eles, proliferação de pragas e contaminação de recursos hídricos (TOZONI-REIS, 2002). Estas informações são facilmente verificadas avaliando os gráficos da Figura 1 em que estão representados os resultados da questão sobre o conhecimento do destino dos resíduos sólidos produzidos na cidade.

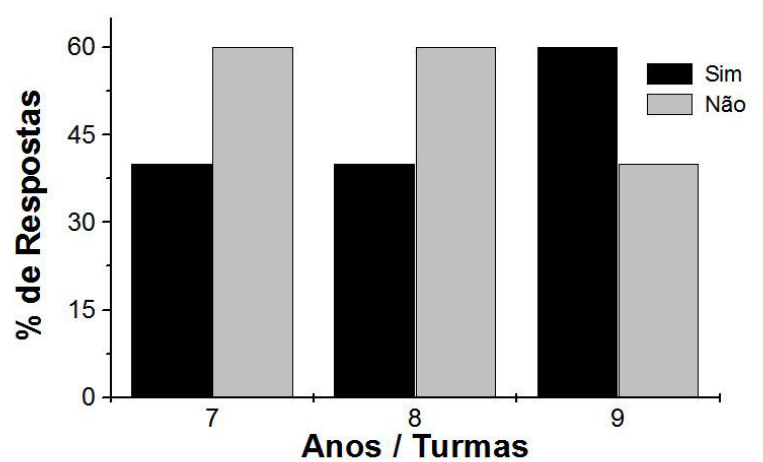

Figura 1: Respostas que os estudantes dos $7^{\circ}$, $8^{\circ}$ e $9^{\circ}$ anos do Ciclo II do Ensino Fundamental apresentaram para a segunda questão do questionário.

Sobre a preocupação da família e dos vizinhos com a produção e o destino dos resíduos sólidos se percebeu que os alunos do $7^{\circ}$ ano, que em média são os mais jovens, se mostraram mais otimistas com essa preocupação, pois consideram que seus familiares e vizinhos são preocupados com a destinação desses resíduos apesar de não saberem o local onde os resíduos são depositados. Já os alunos dos $8^{\circ}$ e $9^{\circ}$ anos se mostraram mais céticos em relação a esse fato, visto que esses percebem a quantidade de resíduo que é descartada pelas ruas da cidade.

Avaliando as respostas da maioria dos alunos que estão indicadas na Figura 2, se percebe que os mesmos não auxiliam na separação dos resíduos produzidos em suas residências. Esse fato é mais intenso com os alunos dos $8^{\circ}$ e $9^{\circ}$ anos. Provavelmente devido ao fato de que em Paranaguá não existem programas específicos de separação e reciclagem desses materiais. Todo o processo ocorre devido a catadores que recolhem e comercializam os materiais sólidos que tem maior valor financeiro agregado. Os estudantes do $7^{\circ}$ ano se mostraram mais habituados a separar esses materiais e demonstram estar mais engajados, provavelmente para auxiliar os catadores que passam em suas ruas arrecadando esses materiais para comercialização. 


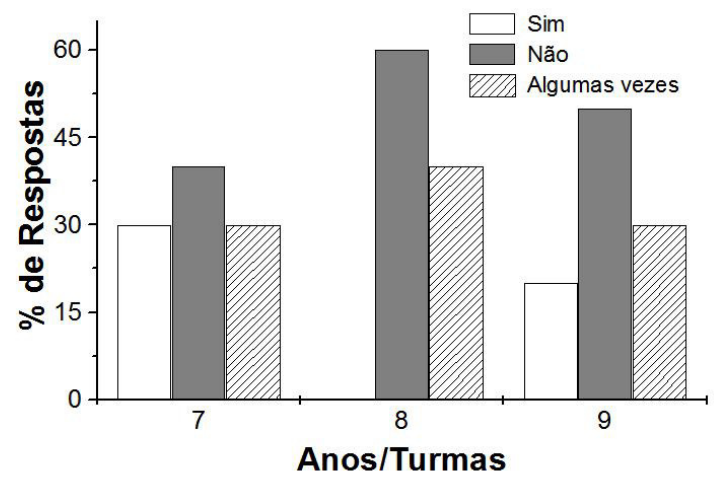

Figura 2: Respostas que os estudantes dos $7^{\circ}$, $8^{\circ}$ e $9^{\circ}$ anos do Ciclo II do Ensino Fundamental apresentaram para a quarta questão do questionário.

$\mathrm{Na}$ quinta questão avaliou-se quais seriam as pessoas que realizavam o processo de reciclagem de resíduos sólidos. A maioria dos alunos do $7^{\circ}$ ano entende que esse processo somente é realizado pelos catadores, visto que $80 \%$ consideram essas as únicas pessoas que encaminham esses materiais para a indústria. Entendendo assim que esse processo somente acontece a partir desse momento, ou seja, a partir do momento em que essas pessoas retiram certos materiais com os quais conseguem algum lucro. Já os alunos dos $8^{\circ}$ e $9^{\circ}$ anos entendem que esse processo é iniciado por todas as pessoas e não somente pelos catadores, portanto entre os $7^{\circ}$ e $8^{\circ}$ anos foi introduzido algum conceito que permite aos alunos perceber que o processo de reciclagem é um processo de cidadania que deve ser iniciado dentro de suas próprias residências e assim reduzindo a contaminação ambiental (JACOBI, 2003).

Em torno de $75 \%$ dos estudantes avaliados nesse estudo indicam que se preocupam em reduzir a produção dos resíduos sólidos, porém durante o processo de discussão aberta, a maioria deles não consegue explicar de que forma os mesmos conseguiriam realizar esse processo. Durante a abertura de discussão se percebeu que alguns alunos do $8^{\circ}$ ano e $9^{\circ}$ ano são incisivos em afirmar que não se preocupam em reduzir esse tipo de resíduos, demonstrando assim que eles não foram atingidos pelo processo de Educação Ambiental que está presente, ou seja, o processo de Educação Ambiental produzido no Brasil ainda não é eficaz e muito menos suficiente para produzir nesses estudantes ações que os tornem cidadãos conscientes com os problemas socioambientais ocasionados pelo descarte incorreto dos resíduos sólidos (GONZÁLEZGAUDIANO, LORENZETTI, 2009; OLIVEIRA, OBARA, RODRIGUES, 2007).

Ao avaliar a questão sobre o processo de reutilização de resíduos sólidos $80 \%$ dos alunos do $8^{\circ}$ ano indicaram que não reutilizavam os materiais que eles compram. Assim os poucos que responderam que reutilizam não conseguiram, durante o processo de discussão, expressar o que e como reutilizam esses materiais. Já os alunos dos $7^{\circ}$ e $9^{\circ}$ anos se mostraram mais divididos em suas respostas, porém da mesma forma que os alunos do $8^{\circ}$ ano, também não conseguiam expressar como e o que eles conseguem reutilizar. Assim, avaliando as suas respostas, se observa que os alunos que indicaram que reutilização os materiais adquiridos conseguem assimilar alguns conceitos ambientais, porém eles apresentam dificuldades em por em prática os mesmos.

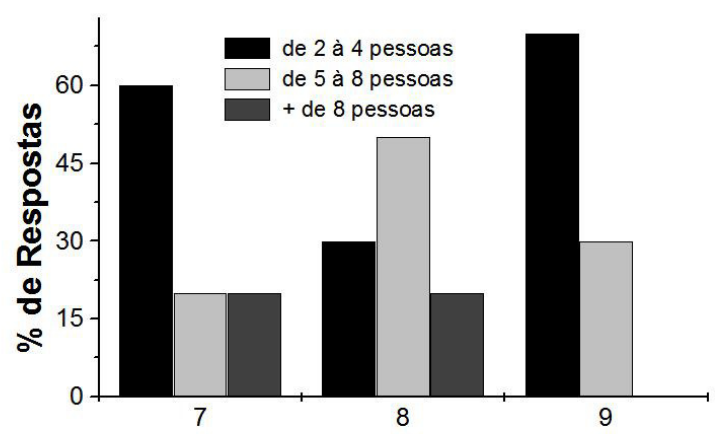

Anos/Turmas

Figura 3: Respostas que os estudantes dos $7^{\circ}$, $8^{\circ}$ e $9^{\circ}$ anos do Ciclo II do Ensino Fundamental apresentaram para a oitava questão do questionário.

$\mathrm{Na}$ questão seguinte foi possível estimar a população envolvida direta e indiretamente nesse estudo. A princípio consideraram-se somente os 90 estudantes, mas durante suas respostas os estudantes envolveram também os seus familiares na produção de resíduos e essa população foi estimada em 354 a 540 pessoas. Para se obter esses valores foram avaliadas as informações da Tabela 2 e também da Figura 3. Obviamente é uma pequena população estatística quando, avaliados os dados produzidos pelo IBGE que estima a população de Paranaguá em 01 de julho de 2015 em 150.660 habitantes (IBGE, 2015). Portanto os valores 
desse estudo serão entre 0,23 a $0,36 \%$ da população da cidade de Paranaguá, PR.

Outro dado estatístico importante obtido foi referente a quantidade de resíduos sólidos produzidos por essa população. Os dados da Figura 4 foram obtidos em números de sacolas de supermercados por dia produzidos de resíduos sólidos. Esses dados foram convertidos em $\mathrm{Kg}$ para relacioná-los com parâmetros da literatura. Com os dados apresentados na Tabela 2 e na Figura 4 foi possível estimar que essa população produzisse $792 \mathrm{Kg} /$ dia de resíduos sólidos.

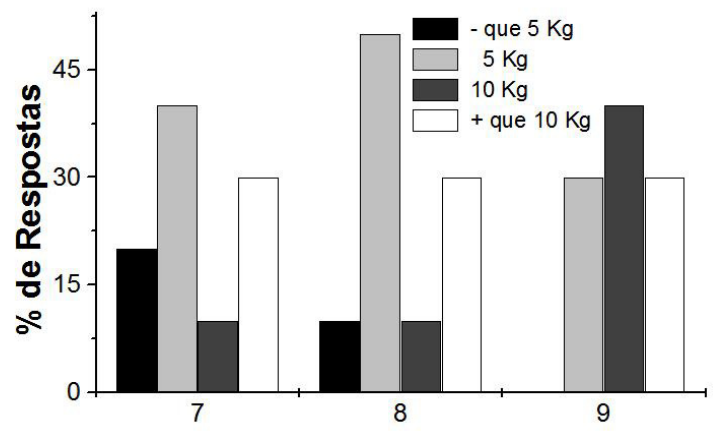

Anos/Turmas

Figura 4: Respostas que os estudantes dos $7^{\circ}$, $8^{\circ}$ e $9^{\circ}$ anos do Ciclo II do Ensino Fundamental apresentaram para a nona questão do questionário.

Portanto quando se determina a produção diária de resíduos sólidos dessa população em estudo, verifica-se que os valores vão de 1,47 a $2,24 \mathrm{Kg}$ de resíduos sólidos/hab.dia. Verifica-se ainda que o valor médio então seja de $1,86 \mathrm{Kg}$ de resíduos/hab.dia. Esse valor é muito superior aquele preconizado e obtido de $1,21 \mathrm{Kg} / \mathrm{hab}$.dia (ABRELPE, 2014) na região sudeste do Brasil no ano de 2014. Já quando se compara com os valores do mesmo período na região sul a diferença é muito maior, visto que a média de resíduo é de 0,73Kg/hab.dia. Revelando assim que os hábitos de consumo e descarte dos moradores dessa cidade, ainda não refletiram as políticas implementadas para reduzir o volume de resíduos (ABRELPE, 2013).

$\mathrm{Na}$ penúltima questão se avaliou as possíveis formas de diminuir a quantidade de resíduos sólidos que são produzidos em cada residência, sendo que os resultados obtidos são visíveis na Figura 5. Das opções indicadas percebe-se que $80 \%$ dos alunos dos $7^{\circ}$ e $9^{\circ}$ anos, bem como $100 \%$ dos alunos do $8^{\circ}$ ano consideram que o processo de redução dos resíduos é eficaz quando se reutiliza e se recicla os mesmos, portanto se percebe aí uma visão conservacionista (SAUVE, 2008). É preocupante observar que ainda $20 \%$ dos alunos do $7^{\circ}$ ano entendem que não é possível reduzir a produção desses resíduos. Embora seja tranqüilizador perceber que $20 \%$ dos alunos pesquisados do $9^{\circ}$ ano conseguem visualizar que é importante diminuir a quantidade de resíduos, comprando menos, ou seja, eles têm uma visão sustentável em relação ao meio ambiente. Adquirir somente aquilo que realmente é necessário, eliminando assim todo tipo de desperdício que está ligado a corrente de sustentabilidade (SAUVE, 2008)

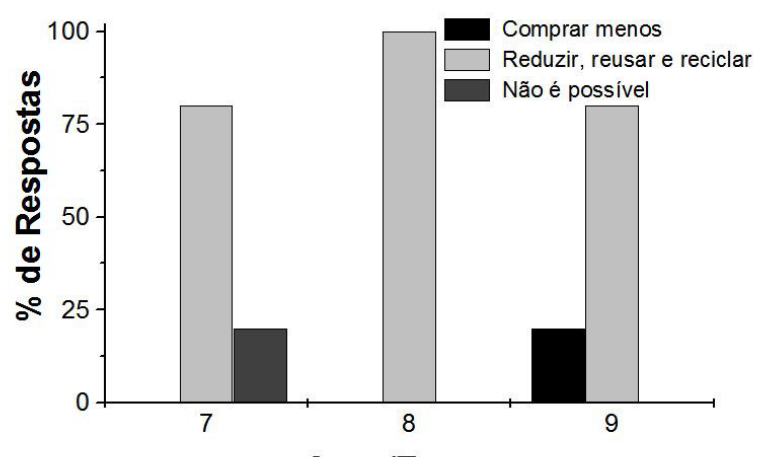

Anos/Turmas

Figura 5: Respostas que os estudantes dos $7^{\circ}$, $8^{\circ}$ e $9^{\circ}$ anos do Ciclo II do Ensino Fundamental apresentaram para a décima questão do questionário.

$\mathrm{Na}$ última questão se verificaram quais seriam as pessoas que poderiam separar os resíduos sólidos, bem como o local aonde esses resíduos poderiam ser separados. A grande maioria dos alunos dos $8^{\circ}$ e $9^{\circ}$ anos entende que esse processo pode ser iniciado por qualquer pessoa e em todos os lugares. Uma pequena minoria dos alunos destas séries acredita que esse processo deve ser realizado em sua totalidade por empresas de reciclagem. Já os alunos do $7^{\circ}$ ano foram mais divididos em suas respostas. Em torno de $50 \%$ acreditam que o processo deve ser realizado em sua totalidade nas empresas de reciclagem, da mesma forma que $100 \%$ e $75 \%$ dos $8^{\circ}$ e $9^{\circ}$ anos, respectivamente. Mas é preocupante como uma pequena percentagem ainda acredita que esse processo deve acontecer nos "lixões". Talvez 
esses sejam alunos que vivem próximos ao "Lixão de Paranaguá", ou ainda, eles ou seus familiares sobrevivem da retirada dos materiais desse local.

Durante o processo de discussão, os alunos também indicaram por quais motivos é necessário se preocupar com a produção de resíduos sólidos. Entre os motivos os principais fatores foram: cuidar do meio ambiente, da cidade onde eles vivem, visto que, esta faz parte do meio ambiente e minimizar os odores desagradáveis e a proliferação de pragas e doenças endêmicas.

Normalmente espera-se que os conteúdos conceituais que auxiliam na construção ativa de capacidades intelectuais para operar símbolos, imagens, ideias e representações que permitam organizar as realidades, sejam importantes para os conteúdos procedimentais. Sendo que estes últimos auxiliam os alunos na construção de instrumentos para analisar, por si só, os resultados que eles obtêm, bem como perceber os processos que colocam em ação para atingir suas metas. Desta forma os conteúdos atitudinais estão relacionados com a formação de atitudes e valores em relação à informação recebida, visando a intervenção do aluno em sua realidade.

Um dos principais fatos relacionados a esses resultados é que na cidade, além dos depósitos de resíduos serem em "Lixões" a população tem como hábito descartar todos os materiais indesejáveis no meio fio de ruas, bem como em áreas onde não existem residências. Proliferando assim pragas, doenças e todo tipo de contaminação ambiental. Atualmente parte dos resíduos produzidos pela população local é encaminhada para um aterro sanitário, porém esta quantidade de resíduos é aquém daquela desejável.

Essa informação é corroborada pela quantidade de resíduos sólidos que são produzidos por habitante quando são avaliados os resultados desse estudo. Esses números são extremamente altos quando comparados com valores médios do país e do mundo. A média de resíduos produzidos e verificados nesse estudo foi de $1,86 \mathrm{Kg} / \mathrm{hab}$.dia enquanto que a média de resíduos produzidos em cidades com alto índice populacional é de $1,20 \mathrm{~kg} / \mathrm{hab}$.dia. Portanto a população avaliada produz valores $55 \%$ maiores do que a média indicada.

Outro fator importante que foi discutido diz respeito a forma de entendimento de conceitos ambientais. A maioria dos alunos que participaram desse estudo apresenta um discurso ambiental conservacionista, porém não apresentaram as mesmas atitudes. Embora se esperasse que eles tivessem tanto o discurso como a atitude de ambientalistas sustentáveis. Já a minoria não apresenta nenhuma atitude ambientalista.

Para que todos esses conceitos, discursos e atitudes sejam realmente assimilados deve se levar um tempo muito maior do que aquele recomendável, pois os estudantes não costumam separar os resíduos produzidos em suas casas. Apresentam um histórico de exemplos negativos de descarte de resíduos por parte dos cidadãos com mais tempo de vida. É possível questionar e realizar cobrança inclusive das escolas que esses alunos frequentam, mas seria extremamente simplório considerar a escola como única culpada desse processo. Desta forma novos trabalhos sobre o meio ambiente devem ser incentivados, principalmente aqueles que envolvam não somente os alunos mas também as suas famílias e a comunidade. Bem como realizar parcerias com outras Secretárias do Município de Paranaguá. Devendo ser um trabalho conjunto, longo e intensivo que faça com que essa realidade caótica pare de existir nesse município.

\section{CONCLUSÕES:}

Com este estudo foi possível concluir que os alunos dos $7^{\circ}, 8^{\circ}$ e $9^{\circ}$ anos do Ciclo II do Ensino Fundamental da escola localizada no município de Paranaguá, PR, afirmam que estão preocupados com o meio ambiente. Porém, as atitudes não são condizentes com o discurso, visto que a maioria não sabe o local em que esses resíduos, produzidos diariamente por eles, são descartados. Essa discrepância entre 0 discurso e as atitudes talvez esteja relacionada com o fato de que os alunos conhecem e assimilam os conceitos e fala que lhes são passados, porém ainda não interiorizaram os mesmos. Conhecem o discurso, porém ainda não conseguem transformar 0 discurso em atitudes.

\section{AGRADECIMENTOS:}

Os autores agradecem aos alunos, 
professores, funcionários e direção da escola estadual onde a pesquisa foi realizada pela colaboração durante esse trabalho.

\section{REFERÊNCIAS:}

1. ABRELPE, Panorama dos Resíduos Sólidos no Brasil 2013. São Paulo: Associação de Empresas de Limpeza Pública e Resíduos Especiais (ABRELPE), 2013, 114p.

2. ABRELPE, Panorama dos Resíduos Sólidos no Brasil 2014. São Paulo: Associação de Empresas de Limpeza Pública e Resíduos Especiais (ABRELPE), 2014, 40p.

3. Bomfim, A. M. Revista Brasileira de Pesquisa em Educação em Ciências. 2013, 12, 67.

4. Brasil. Legislação Brasileira sobre o Meio Ambiente: Série Legislação $n^{0} 45.2^{a} \mathrm{Ed}$. Brasília, DF: Câmara dos Deputados, Edições Câmara, 2010, 967p.

5. Brasil. PCNs Secretaria de Educação Fundamental. Parâmetros curriculares nacionais: meio ambiente, saúde, Vol. 9, Secretaria de Educação Fundamental, Brasília: 1997, 128p.

6. Brasil. Constituição da República Federativa do Brasil. 35 $5^{a}$ Ed. Brasília, DF: Senado, 2012a.

7. Brasil. Lei $\mathrm{N}^{0}$ 9.795. Dispõe sobre a educação ambiental, institui a Política Nacional de Educação Ambiental e dá outras providências. Brasília, DF: Câmara, 1999.

8. Brasil. Lei $\mathrm{N}^{\circ}$ 10.172. Aprova o Plano Nacional de Educação e dá outras providências. Brasília, DF: Câmara, 2001.

9. Brasil. Lei $N^{0}$ 12.608. Institui a Política Nacional de Proteção e Defesa Civil PNPDEC; dispõe sobre o Sistema Nacional de Proteção e Defesa Civil SINPDEC e o Conselho Nacional de Proteção e Defesa Civil CONPDEC; autoriza a criação de sistema de informações e monitoramento de desastres; altera as Leis nos 12.340, de 10 de dezembro de 2010,10.257, de 10 de julho de 2001, 6.766, de 19 de dezembro de 1979, 8.239, de 4 de outubro de 1991, e 9.394, de 20 de dezembro de 1996; e dá outras providências. Brasília, DF: Câmara, 2012b.

10. Carvalho, I. C. M. Educação ambiental: a formação do sujeito ecológico. $6^{a}$ edição. Cortez: São Paulo, 2014.

11. Cuba, M. A. Revista Educação, Cultura e Comunicação. 2010, 1, 23.

12. Dias, S, G. F. Educação ambiental: princípios e práticas. $9^{a}$ edição. Gaia: São Paulo, 2004.

13. González-Gaudiano, E.; Lorenzetti, L. Educação em Revista. 2009, 25,191.

14.http://www.ibge.gov.br/home/estatistica/po pulacao/estimativa2015/estimativa_dou.s $\mathrm{htm}$. Acessada em Janeiro de $201 \overline{6}$.

15. Jacobi, P. Cadernos de Pesquisa, 2003, 118, 189.

16. Moradillo, E. F.; Oki, M. C. M. Química Nova, 2004, 27, 332.

17. Oliveira, A. L.; Obara, A. T.; Rodrigues, M. A. Revista Electrónica de Enseñanza de las Ciencias. 2007, 6, 471.

18. Santos, W. L. P. Ciência \& Ensino, 2007, 1.

19. Sauve, L. Uma Cartografia das Correntes em Educação Ambiental. In: Sato, M; Carvalho, I. C. M. (Orgs.). Educação Ambiental: Pesquisa e Desafios. Artmed: Porto Alegre, 2008.

20. Tozoni-Reis, M. F. C. Ciência \& Ensino, 2002, 8, 83. 
Tabela 1: Questionário realizado para avaliar o conhecimento, que os estudantes dos $7^{\circ}, 8^{\circ}$ e $9^{\circ}$ anos do Ciclo II do Ensino Fundamental tem sobre o meio ambiente e sobre a separação dos resíduos sólidos produzidos diariamente em suas residências.

\section{QUESTÕES Idade: Série:}

1) Você se preocupa com o meio ambiente?

( ) sim ( ) não ( ) algumas vezes

2) Você sabe aonde vai parar o resíduo sólido produzido em sua casa?

( ) $\operatorname{sim}$ ( ) não

3) No bairro onde você mora as pessoas se preocupam com o resíduo sólido produzido?

( ) sim ( ) não ( ) algumas vezes

4) Em sua casa o resíduo sólido é separado?

( ) sim ( ) não ( ) algumas vezes

5) Você sabe quem pode reciclar os resíduos sólidos?

( ) catadores (I) não dá para reciclar ( ) todas as pessoas

6) Você se preocupa em reduzir o resíduo sólido produzido em sua casa?

$\begin{array}{lll}\text { ( ) } \operatorname{sim} \quad \text { ( ) não ( ) algumas vezes } & \end{array}$

7) Você reutiliza alguma coisa que compra?

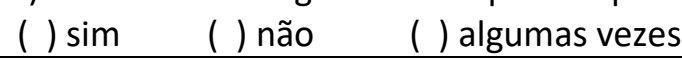

8) Quantas pessoas moram em sua casa?

$\begin{array}{lll}\text { ( ) de } 2 \text { à } 4 & (1) \text { de } 5 \text { à } 8 & \text { ( ) mais de } 8\end{array}$

9) Qual é o volume de resíduo sólido produzido em sua casa por dia?

$\begin{array}{lllll}\text { ( ) menos do que } 10 \mathrm{~L} & \text { ( ) } 10 \mathrm{~L} & \text { ( ) } 20 \mathrm{~L} & \text { ( ) mais do que } 20 \mathrm{~L}\end{array}$

10) Como diminuir a quantidade de resíduos sólidos produzida em casa?

( ) comprando menos ( ) reduzindo, reutilizando e reciclando ( ) não é possível

11) Em que local se pode realizar a separação dos resíduos sólidos?

$\begin{array}{lll}\text { ( ) no lixão ( ) nas empresas de reciclagem ( ) em todos os lugares } & \end{array}$ 
Tabela 2: Número de respostas obtido no questionário realizado e apresentado na Tabela 1.

\begin{tabular}{|c|c|c|c|}
\hline Questões & 70 ANO & 8 ANO & 9 ANO \\
\hline 1 & $\begin{array}{l}\text { (24) sim } \\
\text { (0) não } \\
\text { (6) às vezes }\end{array}$ & $\begin{array}{l}\text { (21) sim } \\
\text { (0) não } \\
\text { (9) às vezes }\end{array}$ & $\begin{array}{l}\text { (30) sim } \\
\text { (0) não } \\
\text { (0) às vezes }\end{array}$ \\
\hline 2 & $\begin{array}{l}\text { (12) sim } \\
\text { (18) não }\end{array}$ & $\begin{array}{l}\text { (12) sim } \\
\text { (18) não }\end{array}$ & $\begin{array}{l}\text { (18) sim } \\
\text { (12) não }\end{array}$ \\
\hline 3 & $\begin{array}{l}\text { (15) sim } \\
\text { (0) não } \\
\text { (15) às vezes }\end{array}$ & $\begin{array}{l}\text { (9) sim } \\
\text { (9) não } \\
\text { (12) às vezes }\end{array}$ & $\begin{array}{l}\text { (6) sim } \\
(12) \text { não } \\
(12) \text { às vezes }\end{array}$ \\
\hline 4 & $\begin{array}{l}\text { (9) } \operatorname{sim} \\
\text { (12) não } \\
\text { (9) às vezes }\end{array}$ & $\begin{array}{l}\text { (0) sim } \\
(18) \text { não } \\
(12) \text { às vezes }\end{array}$ & $\begin{array}{l}\text { (6) sim } \\
\text { (15) não } \\
\text { (9) às vezes }\end{array}$ \\
\hline 5 & $\begin{array}{l}\text { (24) catadores } \\
\text { (0) não dá para reciclar } \\
\text { (6) todas as pessoas }\end{array}$ & $\begin{array}{l}\text { (6) catadores } \\
\text { (0) não dá para reciclar } \\
(24) \text { todas as pessoas }\end{array}$ & $\begin{array}{l}\text { (6) catadores } \\
\text { (3) não dá para reciclar } \\
\text { (21) todas as pessoas }\end{array}$ \\
\hline 6 & $\begin{array}{l}\text { (24) sim } \\
\text { (6) não } \\
\text { (0) às vezes }\end{array}$ & $\begin{array}{l}\text { (18) sim } \\
\text { (9) não } \\
\text { (3) às vezes }\end{array}$ & $\begin{array}{l}\text { (18) sim } \\
\text { (6) não } \\
\text { (6) às vezes }\end{array}$ \\
\hline 7 & $\begin{array}{l}\text { (12) sim } \\
\text { (12) não } \\
\text { (6) às vezes }\end{array}$ & $\begin{array}{l}\text { (6) sim } \\
\text { (24) não } \\
\text { (0) às vezes }\end{array}$ & $\begin{array}{l}\text { (15) sim } \\
\text { (12) não } \\
\text { (3) às vezes }\end{array}$ \\
\hline 8 & $\begin{array}{l}\text { (18) de } 2 \text { à } 4 \\
\text { (6) de } 5 \text { à } 8 \\
\text { (6) mais de } 8\end{array}$ & $\begin{array}{l}\text { (9) de } 2 \text { à } 4 \\
\text { (15) de } 5 \text { à } 8 \\
(6) \text { mais de } 8\end{array}$ & $\begin{array}{l}\text { (21) de } 2 \text { à } 4 \\
\text { (9) de } 5 \text { à } 8 \\
\text { (0) mais de } 8\end{array}$ \\
\hline 9 & $\begin{array}{l}\text { (6) menos do que } 10 \mathrm{~L} \\
\text { (12) } 10 \mathrm{~L} \\
\text { (3) } 20 \mathrm{~L} \\
\text { (9) mais do que } 20 \mathrm{~L}\end{array}$ & $\begin{array}{l}\text { (3) menos do que } 10 \mathrm{~L} \\
\text { (15) } 10 \mathrm{~L} \\
\text { (3) } 20 \mathrm{~L} \\
\text { (9) mais do que } 20 \mathrm{~L}\end{array}$ & $\begin{array}{l}\text { (0) menos do que } 10 \mathrm{~L} \\
\text { (9) } 10 \mathrm{~L} \\
\text { (12) } 20 \mathrm{~L} \\
\text { (9) mais do que } 20 \mathrm{~L}\end{array}$ \\
\hline 10 & $\begin{array}{l}\text { (0) comprando menos } \\
\text { (24) reduzindo, } \\
\text { reutilizando e reciclando } \\
\text { (6) não é possível }\end{array}$ & $\begin{array}{l}\text { (0) comprando menos } \\
\text { (30)reduzindo, } \\
\text { reutilizando e reciclando } \\
\text { (0) não é possível }\end{array}$ & $\begin{array}{l}\text { (6) comprando menos } \\
\text { (24) reduzindo, } \\
\text { reutilizando e reciclando } \\
\text { (0) não é possível }\end{array}$ \\
\hline 11 & $\begin{array}{l}\text { (3) no lixão } \\
\text { (15) nas empresas de } \\
\text { reciclagem } \\
\text { (12) em todos os lugares }\end{array}$ & $\begin{array}{l}\text { (0) no lixão } \\
\text { (6) nas empresas de } \\
\text { reciclagem } \\
\text { (24)em todos os lugares }\end{array}$ & $\begin{array}{l}\text { (3) no lixão } \\
\text { (6) nas empresas de } \\
\text { reciclagem } \\
\text { (21) em todos os lugares }\end{array}$ \\
\hline
\end{tabular}

PERIÓDICO TCHÊ QUÍMICA • www.periodico.tchequimica.com • Vol. 14 N. 28

• ISSN 1806-0374 (impresso) • ISSN 1806-9827 (CD-ROM) • ISSN 2179-0302 (meio eletrônico) (C) 2017. Porto Alegre, RS. Brasil 